\title{
BASAL MASS BALANCE ALONG A FLOW LINE ON RONNE ICE SHELF, ANTARCTICA
}

\section{(Abstract)}

by

\author{
A. Jenkins and C.S.M. Doake
}

(British Antarctic Survey, Natural Environment Research Council, High Cross, Madingley Road, Cambridge CB3 OET, England)

\section{ABSTRACT}

Recent glaciological work on Ronne Ice Shelf has focused on an assumed flow line which extends from Rutford Ice Stream grounding line to the ice front. Results from doppler satellite surveying and radio echo-sounding are used in kinematic calculations to determine the basal mass balance, assuming the flow line to be in a steady state. Models suggest that basal melting dominates over most of the flow line and is most pronounced at the extremities. In the region within $300 \mathrm{~km}$ of the grounding line and over the final $45 \mathrm{~km}$ before the ice front, at least $1 \mathrm{~m} / \mathrm{a}$ on average must melt away to maintain the observed velocity and thickness profile. More gentle melting occurs over about half the remaining distance, but in a region between 130 and $300 \mathrm{~km}$ in from the ice front, basal freezing must occur at an average rate of about $0.1 \mathrm{~m} / \mathrm{a}$ to maintain a steady state. The existence of a thin layer of saline ice underlying the ice shelf, which persists for a further $80 \mathrm{~km}$ down-stream before being melted away entirely, is consistent with the weak returns observed during both airborne and ground-based radio echo-sounding in this region.

\section{GEDANKENEXPERIMENTE: ASSESSING FIELD-PROGRAM EFFECTIVENESS BY NUMERICAL SIMULATIONS \\ (Abstract)}

\author{
by \\ M.A. Lange \\ (Alfred Wegener Institute for Polar and Marine Research, Postfach 120161 , \\ Columbusstraße, D-2850 Bremerhaven, Federal Republic of Germany)
}

and

D.R. MacAyeal

(University of Chicago, Department of the Geophysical Sciences, 5734 S. Ellis Avenue, Chicago, IL 60637, U.S.A.)

\begin{abstract}
Glaciological field programs may be regarded as imperfect sampling schemes designed to provide fundamental physical information on the dynamics and climatic sensitivity of the Antarctic ice sheet. Uncertainty arises as a result of technical and human factors such as: (i) logistic and financial constraints, (ii) measurement errors, (iii) low spatial resolution (see (i)), and (iv) (possibly!) misconceptions on the part of glaciologists who plan and execute field work. Regardless of such uncertainty, we depend on field data as the fundamental intellectual driving force of glaciology. Introspective evaluation of our field methods and program designs is thus reasonable, and perhaps necessary, to insure that our field programs are indeed satisfying their intended purpose.

In our study, we conduct a variety of Gedankenexperimente (imaginary field programs), which sample an arbitrary, idealized ice shelf, subject to fluctuations and climatic changes on a variety of time and space scales. The "actual" behavior of this ice shelf is produced by a time-dependent numerical simulation of ice-shelf evolution under specified forcings, using a model
\end{abstract}

based on that of Lange and MacAyeal (1986). Each Gedankenexperiment consists of a spatially incomplete sampling of the model grid data at a particular moment in the evolution of the ice shelf (just as a real field program presently would sample the current state of an Antarctic ice shelf). The spatial sampling patterns are based on particular techniques commonly used in field programs (Kohnen 1985, Bindschadler and others 1987, Doake and others 1987, Shabtaie and Bentley 1987). Such sampling is designed to simulate field techniques such as airborne radio echo-sounding, surface geodetic measurements, aerial photography, and satellite altimetry (Fig. 1). We also add "random noise" to the sampled data, to simulate instrumental and navigational uncertainties.

Having sampled the idealized ice shelf by using an imaginary field program, we "process" the supposed field data in order to test how well it reveals certain aspects of ice-shelf flow and evolution. This test is conducted by comparing the field-program results with the "known" behavior (by definition) of the numerical simulation. A variety of field-program design schemes are compared on 